\title{
Normal Absorption in Thai Subjects with Non-specific Jejunal Abnormalities*
}

\author{
FRANK J. TRONCALE, $†$ M.D.; GERALD T. KEUSCH,ł M.D. ; LOUIS H. MILLER,§ M.D. \\ RAY A. OLSSON,\| M.D.; RICHARD D. BUCHANAN,§ M.D.
}

Brit. med. Y., 1967, 4, 578-580

There is a growing belief that subclinical tropical sprue is widespread in tropical countries (Klipstein, 1967). This opinion is based on studies of asymptomatic adults in India (Baker et al., 1962), Pakistan (Russell et al., 1966 ; Lindenbaum et al., 1966b), and Thailand (Sprinz et al., 1962), in whom jejunal histological abnormalities and impaired xylose absorption were frequently found. Recent studies in Haiti by Klipstein et al. (1966) show that this condition is very common in individuals complaining of one or more symptoms of the disease. The ease with which the same histological and biochemical abnormalities could be demonstrated in asymptomatic subjects led these workers to speculate that tropical sprue is a disease with a wide range of expression and that the overt cases represent only a fraction of the total number affected.

Because a jejunal lesion has been found commonly in asymptomatic subjects in Thailand (Sprinz et al., 1962), we undertook to study its functional expression with a wider variety of tests than previously employed in order to assess the lesion as a possible precursor of tropical sprue.

\section{Methods}

Forty volunteer subjects, primarily from two villages on the outskirts of Bangkok, gave informed consent and were admitted to hospital for the studies to be described. There were 22 females aged 16-72 years and 18 males aged 13-45 years. History and physical examination were within normal limits. The following were performed in every subject : complete blood counts, total serum protein, protein electrophoresis, serum phosphorus, calcium, iron, and beta-carotene. Urinalysis and determination of blood urea nitrogen and serum creatinine were also carried out in all subjects and found to be normal by North American standards. Chest $x$-ray examinations, performed in all subjects, were also normal.

Five-hour urinary D-xylose excretion and two-hour serum sylose levels were measured in fasting subjects. All subjects received $25 \mathrm{~g}$. of xylose, except for three who received $0.5 \mathrm{~g} . / \mathrm{kg}$. $(13.7,22.0$, and $22.6 \mathrm{~g}$.). Urine and serum specimens were kept frozen after collection. The xylose determination (Roe and Rice, 1948) was performed within 24 to 48 hours after completion of the test.

Vitamin- $B_{12}$ absorption was measured by the Schilling (1953) technique, ${ }^{57}$ Co vitamin $B_{12}$ (Racobalamin) with intrinsic factor being used. Vitamin-A absorption was tested in fasting subjects by the oral administration of a dose of 260,000 international units mixed in corn oil. Serum levels were measured before and five hours after ingestion of vitamin A (I.C.N.N.D., 1964).

- From the Clinical Research Center and Department of Pathology, Medical Research Laboratory, S.E.A.T.O. Medical Project, Rajavithi Road, Bangkok, Thailand.

t Captain, Medical rorps. Present address: Harvard Medical Unit, Boston City Hospital, Boston, Massachusetts 02118.

† Present address: New England Medical Center Hospitals, Boston, Massachusetts.

S Captain, Medical Corps.

\{ Lieutenant-Colonel, Medical Corps. Present address: Walter Reed Army Institute of Research, Washington, D.C.
For the lactose-tolerance test an oral dose of lactose $(1.5 \mathrm{~g} . /$ kg. body weight) was administered. The glucose-tolerance test was performed with an oral dose of $0.75 \mathrm{~g}$. of glucose $/ \mathrm{kg}$. body weight, an amount equimolar to the glucose content of the lactose in the lactose-tolerance test. Blood glucose was estimated (Technicon AutoAnalyzer method, 1937) before and $15,30,45,60,90$, and 120 minutes after each sugar was administered.

Stools were collected for three to six days and were analysed for fat by the method of van de Kamer et al. (1949). Because fat intake in the average Thai diet is low (I.C.N.N.D., 1962), a daily supplement of $75 \mathrm{~g}$. of butter was given during the collection period. Carmine red dye was given orally to mark the beginning and end of the collection periods.

Fluoroscope examination of the upper gastrointestinal tract, with small-bowel follow-through studies, was also made. (We are indebted to Major Chitti Palavatana for carrying out the $\boldsymbol{x}$-ray studies.)

Small-bowel biopsy specimens were taken from the jejunum with a Crosby biopsy capsule (Crosby and Kugler, 1957) after $x$-ray verification of the position of the capsule. The specimens were orientated with the mucosal side up on filter paper and were fixed in $10 \%$ buffered formalin. Haematoxylin and eosin, periodic acid-Schiff, and iron stains were done on all material. In order to minimize artifacts resulting from tangential cutting, care was taken to ensure that the plane of sectioning was parallel to the long axis of the villi and perpendicular to the luminal surface (Rubin and Dobbins, 1965). Measurements of overall mucosal thickness and villus/crypt ratio were made in eight patients by methods similar to those of Swanson and Thomassen (1965).

\section{Results}

Laboratory data are shown in the Table. Urinary excretion of D-xylose after a $25-\mathrm{g}$. dose was $5.84 \pm 1.54$ (S.D.) g. in 36 subjects. The mean two-hour serum level was $39.8 \pm 7.5$ (S.D.) mg. $/ 100 \mathrm{ml}$. The percentage of xylose excreted by the three subjects given the smaller dose $(0.5 \mathrm{~g} . / \mathrm{kg}$. body weight $)$ was comparable to that after a $25-\mathrm{g}$. dose. Mild diarrhoea consisting of two to four watery stools occurred after ingestion of the 25 -g. dose in three subjects. Five-hour urine volumes were above $225 \mathrm{ml}$. in all subjects tested.

Little or no increase in blood glucose occurred after oral lactose administration in the 39 subjects tested (Fig. 1), the mean maximum rise being $2.97 \pm 3.07 \mathrm{mg} . / 100 \mathrm{ml}$. Diarrhoea, consisting of up to 10 loose stools, or abdominal cramps, or both, occurred in 28 of the 39 subjects.

In contrast with the flat lactose-tolerance test, glucose absorption was usually normal. The mean maximum rise in blood sugar after ingestion of $0.75 \mathrm{~g} . / \mathrm{kg}$. body weight of glucose was $42.5 \pm 20.5$ (S.D.) mg. $/ 100 \mathrm{ml}$. in 33 subjects (Fig. 1). Only four subjects showed a rise of less than $20 \mathrm{mg} . / 100 \mathrm{ml} .(7,15$, 16 , and $19 \mathrm{mg} . / 100 \mathrm{ml}$.). In four other subjects given $100 \mathrm{~g}$. of glucose the mean maximum rise in blood sugar was 61.5 mg./100 ml. 
Vitamin- $B_{12}$ absorption was normal in 33 out of 34 subjects tested (Fig. 2). One subject with a haemoglobin of $12.4 \mathrm{~g}$. excreted $4 \%$ of the dose.

Stool fat excretion averaged $2.31 \pm 1.37 \mathrm{~g}$./day in 35 subjects tested. The values were below $5 \mathrm{~g}$. in all except two, in whom the fat excretion was 6.3 and $6.8 \mathrm{~g}$./day (Fig. 2).

Vitamin-A tolerance in 24 out of 27 subjects showed a rise of more than $125 \mu \mathrm{g} . / 100 \mathrm{ml}$. above the control value (Gardner and Perez-Santiago, 1956).

The mean serum total cholesterol was $177.5 \pm 31 \mathrm{mg} . / 100 \mathrm{ml}$. in 25 subjects tested. There was no correlation between xylose excretion and serum cholesterol (Robins et al., 1967).

The following mean levels $( \pm$ S.D.) were obtained (the number of subjects tested is in parentheses): serum calcium, $9.31 \pm 0.49$ mg./100 ml. (29); serum beta-carotene, $133.1 \pm 65.0 \mu \mathrm{g} . / 100$

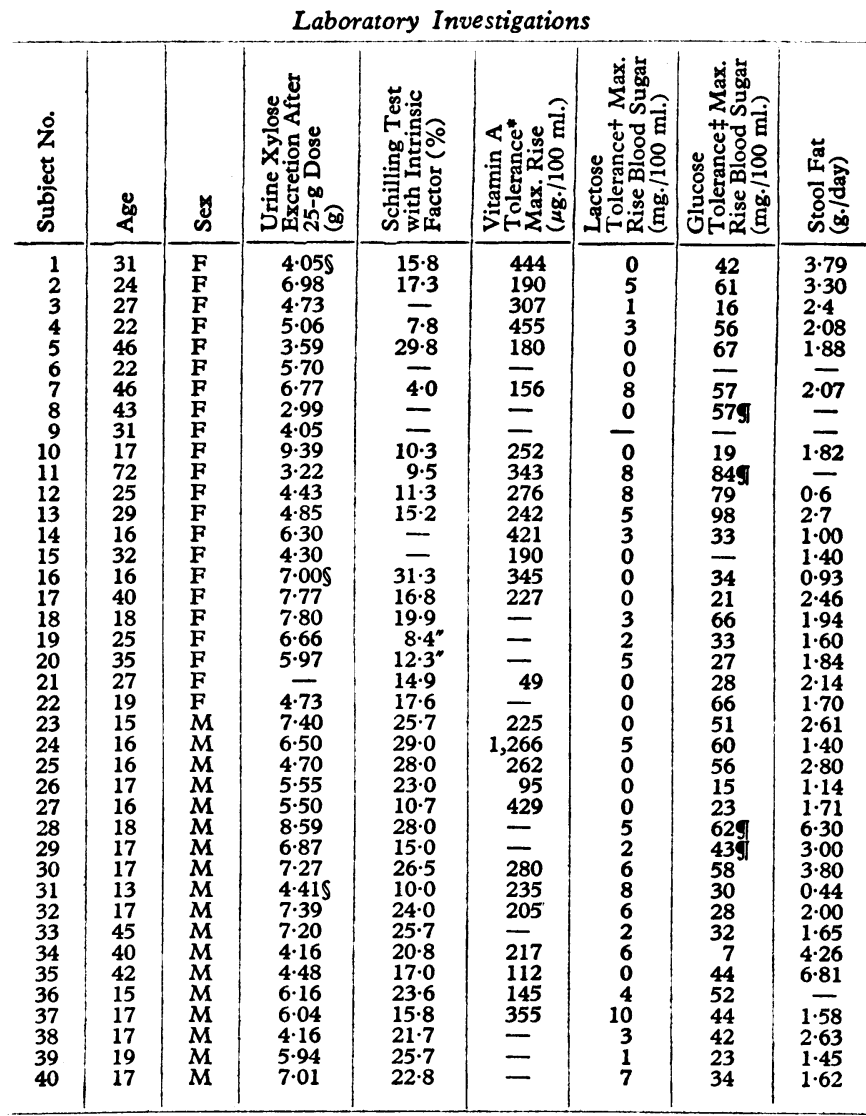

* Test dose 260,000 r.u. + Test dose $1.5 \mathrm{~g}$. $/ \mathrm{kg}$. body weight. $\$$ Test dose $0.75 \mathrm{~g} . /$ $\mathrm{kg}$. body weight.
T Test dose $100 \mathrm{~g}$.

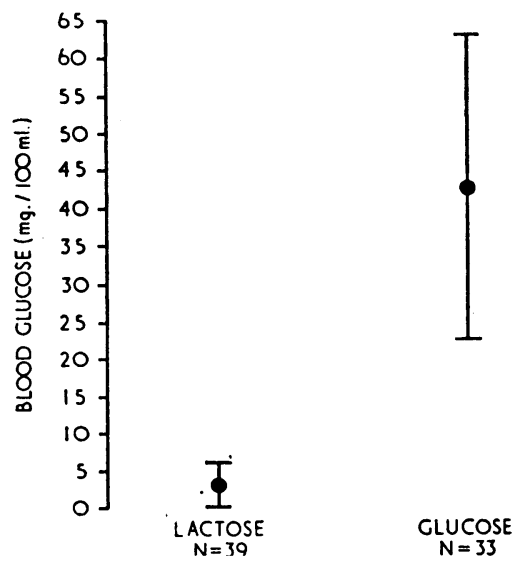

Fig. 1.-Comparison of mean maximal rise in blood glucose over fasting value in Thai subjects after lactose- and glucosetolerance tests \pm 1 S.D. ml. (34) ; serum albumin, $4.18 \pm 0.56$ g. $/ 100 \mathrm{ml}$. (32) ; haemoglobulin, males $13.8 \pm 1.9$ g. $/ 100 \mathrm{ml}$. (18), females $12.1 \pm 1.2$ g./100 $\mathrm{ml}$ (22).

Fifteen subjects were found to harbour the following smallintestinal parasites: Ascaris alone in 11, Ascaris and hookworm in one, hookworm alone in one, hookworm and Strongyloides in one, and Giardia lamblia in one. No difference in absorption tests was noted between these subjects and the 24 whose stools were negative for parasites, with one exception. Subject 8, whose stools contained $G$. lamblia, excreted the lowest xylose recorded-2.99 g.

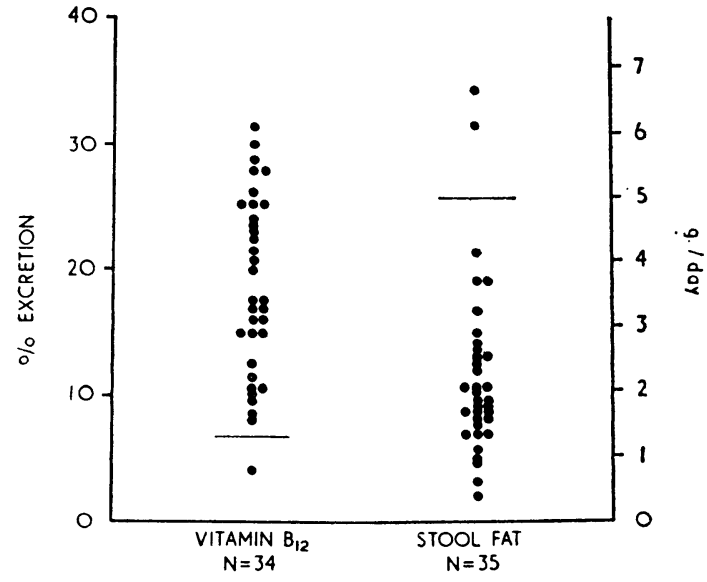

FIG. 2.-Individual values for cobalt-57 vitamin $\mathbf{B}_{\mathbf{1}}$, urinary excretion (Schilling test) and for stool fat excretion in Thai subjects. Horizontal lines indicate lower and upper limits of normal, respectively, by Western
standards.

The small-bowel pattern by $x$-ray examination was normal in the 29 subjects studied, except for mild mucosal irregularity in the ileum of one. In six subjects wormlike objects, probably ascarids, were seen in the mid-ileum.

A jejunal biopsy was obtained in each of the 40 subjects. The specimens were reasonably uniform in appearance, with the same mild histological abnormalities as noted in a previous report from Thailand (Sprinz et al, 1962). Under the dissectingmicroscope the villi were irregular in height and thickness

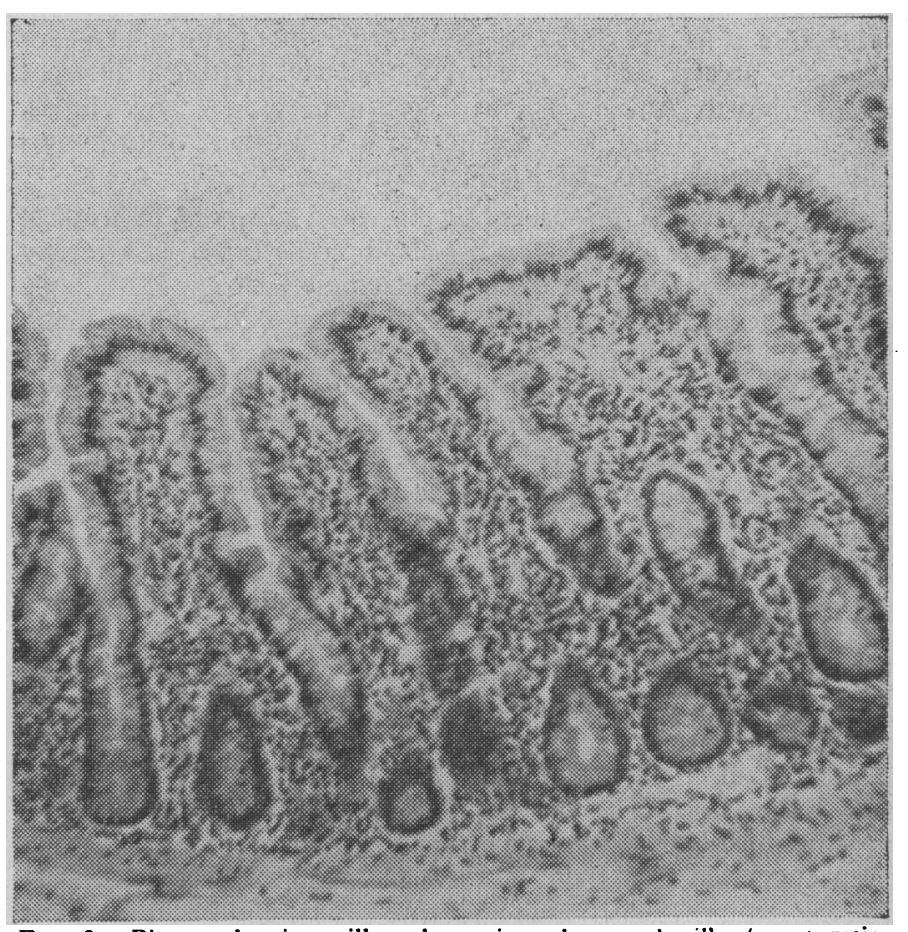

FIG. 3.-Biopsy showing villus shortening, decreased villus/crypt ratio, and increased cellularity of the lamina propria. (Haematoxylin and 
and usually leaflike or tonguelike in overall shape. In no specimen did fingerlike forms predominate. A flat or convoluted mucosal pattern was not seen in any patient. Under the light microscope the most impressive changes were villusshortening with a decrease in the villus/crypt ratio, and uniform infiltration of the lamina propria with plasma cells and lymphocytes (Fig. 3). In the eight biopsies measured the average total villus/crypt thickness was $520 \mu$ (range 420-630 $\mu$ ) and the average villus/crypt ratio was $2.3: 1$ (range $1.9: 1-3.1: 1$ ). Periodic-acid-Schiff and iron stains were unremarkable. No correlation was noted between the degree of microscopic or gross abnormality of the biopsies and any of the laboratory findings.

\section{Discussion}

In this population of asymptomatic Thai subjects the results of fat, vitamin- $B_{12}$, vitamin-A, and glucose-absorption tests were comparable to the results obtained in North American subjects (Sheehy and Floch, 1964). Xylose and lactose absorption and the histological appearance of the jejunal mucosa were different, however. Changes of similar degree have been found by others in apparently healthy subjects and interpreted as indications of subclinical intestinal disease (Baker et al., 1962 ; Russell et al., 1966 ; Lindenbaum et al., 1966b). Is there any evidence to support this contention?

Urinary xylose excretion after a $25-\mathrm{g}$. dose in this population $(5.84 \pm 1.54$ g.) is essentially the same as Gardner and PerezSantiago (1956) (5.60 \pm 0.60 g.) and Butterworth et al. (1959) $(5.70 \pm 1.40$ g.) have reported from Puerto Rico, and Lindenbaum et al. (1966b) from East Pakistan (5.38 \pm 1.57 g.). The Thai results are significantly lower than those of a group of North Americans studied in our laboratory (Keusch et al., unpublished data). A similar difference was found by Lindenbaum et al. (1966b) between "protected" Westerners living in Pakistan and Pakistanis. While the reasons for this mild reduction in xylose excretion are not apparent, it is important to point out that these results are clearly higher than values found in classical tropical sprue (Sheehy and Floch, 1964).

The xylose excretion in the present study and in Pakistanis (Lindenbaum et al., 1966a) has a bell-shaped distribution. Therefore it is not valid to use a criterion of normality-for example, greater than $5 \mathrm{~g}$. excretion-derived from a different group (North Americans), as is customary in many clinics. Arbitrarily applying such a criterion would divide these homogeneous populations studied in the tropics.

Though lactose malabsorption has been observed in tropical sprue (Bayless et al., 1964), it has also been described in a variety of other gastrointestinal diseases (Haemmerli et al., 1965), as a possible genetically controlled enzyme defect (Cook and Kajubi, 1966), and in a surprisingly high percentage of normal adults (Friedland, 1965). The cause in the Thai is not clear. However, in view of what is apparently a universal occurrence of lactose malabsorption in Thais, the test is of no value in this population as a screening test for tropical sprue (Sherhy and Anderson, 1965).

Interpretation of the very mild non-specific jejunal abnormality is also difficult. Similar histological changes have been reported in kwashiorkor (Burman, 1965), hookworm disease (Tandon et al., 1966), viral illnesses (Sheehy et al., 1964), rosacea (Watson et al., 1965), acute diarrhoea (Lindenbaum, 1965), and after triparanol administration (McPherson and Summerskill, 1963). None of these conditions was present in our subjects. What, then, is the relation between this nonspecific histological abnormality and tropical sprue ? It has been suggested that there is a spectrum of small-bowel disease in the tropics which ranges from mild and asymptomatic malabsorption to overt sprue (Klipstein et al., 1966). Furthermore, this coexistence of tropical sprue and milder forms of jejunal abnormality in the same tropical population has been cited as evidence for an association between the two processes (Klipstein, 1967). However, our results fail to support this contention, since intestinal function in Thai subjects with nonspecific jejunal abnormalities is different from that in overt tropical sprue. Furthermore, Pakistanis with similar histological changes failed to show improvement in absorption tests after treatment with tetracycline or folic acid, which are usually effective in tropical sprue (Lindenbaum et al., 1966a).

\section{Summary}

Forty asymptomatic Thai subjects were studied for evidence of tropical sprue by means of the following tests: xylose excretion, ${ }^{57} \mathrm{Co}$ vitamin- $\mathrm{B}_{12}$ and vitamin-A absorption, faecal fat excretion, lactose and glucose tolerance, small-intestine radiographs, and jejunal biopsy. Xylose excretion was lower than in North American subjects but above the range expected in tropical sprue. Lactose malabsorption and mild non-specific histological abnormalities of the jejunal mucosa were present in all. The other studies showed nothing abnormal. These findings were considered insufficient to support a diagnosis of subclinical tropical sprue, and thus we have no evidence for sprue as a widespread disease in Thailand.

We are indebted to Colonel Edward H. Johnston for helpful criticism of the manuscript ; to Captain S. W. Nye for helpful discussion in the early stages of the work; to Mrs. Yupa Kasemsant for her help in providing the subjects used in the study ; to Miss Natamnuay Soparpun for providing nursing supervision of the study subjects ; and to the Laboratory Service of the Clinical Research Center, S.E.A.T.O. Medical Research Laboratory, for performing the chemical analyses.

Requests for reprints should be addressed to Lieutenant-Colonel Ray A. Olsson.

\section{REFERENCES}

Baker, S. J., Ignatius, M., Mathan, V. I., Vaish, S. K., and Chacko C. C. (1962). In Ciba Foundation Study Group No. 14 on Intestinal Biopsy, edited by G. E. W. Wolstenholme and M. P. Cameron, Biopsy, edited by G. E. W.
p. 84. Boston, Massachusetts.

Bayless, T. M., Walter, W., and Barber, R. (1964). Clin. Res., 12, 445. Burman, D. (1965). Arch. Dis. Childh., 40, 526.

Butterworth, C. E., Perez-Santiago, E., Martinez de Jesus, J., and Santini, R. (1959). New Engl. 7. Med., 261, 157

Cook, G. C. and Kaiubi, S. K. (1966). Lancet, 1, 725.

Crosby, W. H., and Kugler, H. W. (1957). Amer. Y. dig. Dis., 2, 236.

Friedland, N. (1965). Arch. intern. Med., 116, 886.

Griedland, N. (1965). Arch. intern. Med., 116, 886. 8 . 98, 467.

Gardner, F. H., and Perez-Santiago, E. (1956). Ibid.,

Interdepartmental, Committee on Nutrition for National Defense (1962). Kingdom of Thailand, Nutrition Survey. Washington.

(1964). Laboratory Manual for Use in Nutrition Surveys, pp. 29 38. Washington.

Keusch, G. T., Plaut, A. G., and Troncale, F. J. Unpublished observations.

Klipstein, F. A. (1967). Ann. intern. Med., 66, 622.

Samloff, I. M., and Schenk, E. A. (1966). Ibid., 64575.

Lindenbaum, J. (1965). Brit. med. F., 2, 326.

Alam, A. K. M. J., and Kent, T. H. (1966a). Ibid., 2, 1616

二 Kent, T. H., and Sprinz, H. (1966b). Ann. intern. Med., 65, 1201

McPherson, J. R., and Summerskill, W. H. J. (1963). Gastroenterology, 44, 900 .

Robins, S. J., Garcia-Palmieri, M., and Rubio, C. (1967). Ann. intern Med. 66, 556.

Roe, J. H., and Rice, E. W. (1948). 9. biol. Chem., 173, 507.

Rubin, C. E., and Dobbins, W. O. (1965). Gastroenterology, 49, 676.

Russell, P. K aziz, M D. Ahmad, N., Kent, T. H., and Gangarosa, E. J. (1966). Amer. F. dig. Dis., 11, 296.

Schilling, R. F. (1953). F. Lab. clin. Med., 42, 860

Sheehy, T. W., and Anderson P. R. (1965). Lancet, 2, 1.

Artenstein, M. S., and Green, R. W. (1964). F. Amer. med. Ass., $190,1023$.

and Floch, M. H. (1964). The Small Intestine. Its Function and Diseases. New York.

Sprinz, H., Sribhibhadh, R., Gangarosa, E. J., Benyajati, C., Kundel, D., and Halstead S. (1962). Amer. 7. clin. Path., 38, 43.

Swanson, V. L. and Thomassen, R. W. (1965). Amer. 7. Path. 46, 511. Tandon, B. N., Das, B. C., Saraya, A. K., and Deo, M. G. (1966). Brit med. $\dot{y} ., 1,714$.

Technicon AutoAnalyzer Method. File No. N-2A, based on the method of W. S. Hoffman (1937), ₹, biol. Chem., 120, 51 .

van de Kamer, J. H., ten Bokkel Huinink, H., and Weyers, H. A. (1949). Ibid., 177, 347 .

Watson, W. C., Paton, E., and Murray, D. (1965). Lancet, 2, 47. 